Int. J. Electrochem. Sci., 12 (2017) $782-796$

\title{
Inhibition effect of Ilex kudingcha C.J. Tseng (Kudingcha) extract on J55 Steel in 3.5wt\% NaCl Solution Saturated with $\mathrm{CO}_{2}$
}

Songsong Chen ${ }^{3}$, Ambrish Singh ${ }^{3}$, Yuanluqi Wang ${ }^{3}$, Wanying Liu ${ }^{3}$, Kuanhai Deng ${ }^{2}$, Yuanhua Lin ${ }^{1,2,3, *}$

${ }^{1}$ State Key Laboratory of Oil and Gas Reservoir Geology and Exploitation, Southwest Petroleum University, Chengdu 610500, Sichuan, China

${ }^{2}$ CNPC Key Lab for Tubular Goods Engineering, Southwest Petroleum University, Chengdu 610500, Sichuan, China

${ }^{3}$ School of Materials Science and Engineering, Southwest Petroleum University, Chengdu, Sichuan 610500, China.

*E-mail: yhlin28@163.com

doi: $10.20964 / 2017.01 .21$

Received: 11 September 2016 / Accepted: 20 November 2016 / Published: 12 December 2016

The corrosion effect on $\mathrm{J} 55$ steel in $3.5 \mathrm{wt} \% \mathrm{NaCl}$ solution saturated with $\mathrm{CO}_{2}$ by ethanol extract of Ilex kudingcha C.J. Tseng (KDC) leaves has been studied using fourier transform infrared spectroscopy (FTIR), potentiodynamic polarization, electrochemical impedance spectroscopy (EIS) and scanning electron microscopy (SEM) methods. The results showed that KDC can be used as a good green inhibitor in the test solution. Inhibition efficiency increases with increasing the inhibitor concentration and KDC extract act as a mixed-type inhibitor. Adsorption behavior of the KDC extracts on J55 steel surface is also studied by Langmuir, Frumkin and Temkin isotherms and the data fitting results suggested that Langmuir isotherm model is the most suitable adsorption model.

Keywords: Corrosion inhibition; J55 steel; Adsorption isotherm; Electrochemical study

\section{FULL TEXT}

(C) 2017 The Authors. Published by ESG (www.electrochemsci.org). This article is an open access article distributed under the terms and conditions of the Creative Commons Attribution license (http://creativecommons.org/licenses/by/4.0/). 